\title{
The Impact of Environmental Sensing Strategies on the Organizational Effectiveness: Evidence from Jordan
}

\author{
Eyad Taha Al - Rawashdeh ${ }^{1} \&$ Ghazi Ali Al-Badayneh ${ }^{2}$ \\ ${ }^{1}$ School of Business, Tafila Technical University, Tafila, Jordan \\ Correspondence: Ghazi Ali Al-Badayneh, School of Business, Tafila Technical University, Tafila, Jordan.
}

Received: May 17, 2019

Accepted: June 12, $2019 \quad$ Online Published: June 18, 2019

doi:10.5539/ibr.v12n7p1

URL: https://doi.org/10.5539/ibr.v12n7p1

\begin{abstract}
The purpose of study is to identifying the impact of environmental sensing strategies on the organizational effectiveness among Jordanian commercial banks. In order to achieve the study objective, a questionnaire was designed and distributed to 175 -members study community from the managerial level (director, deputy director and head of department). The appropriate statistical methods were used to analyze the data.

The result of the study reveals that, the level of applying environmental sensing strategies in Jordanian commercial banks has reached a high level. The level of organizational effectiveness in Jordanian commercial banks, has also reached a high level. There is a statistically significant impact of environmental sensing strategies (flexibility strategy, containment strategy, and forecasting strategy) on the organizational effectiveness as a whole and on its dimensions, individually, (availability of information, stability).

The study reached a number of recommendations, the most important are: creating a system of incentives and rewards for the employees to motivate them to work and to demonstrate distinguished abilities to interpret and clarify the information in a way that serves the organization.
\end{abstract}

Keywords: environmental sensing strategies, organizational effectiveness, Jordanian commercial banks

\section{Introduction}

The banking sector faces serious strategic and competitive challenges due to the rapid changes in the global business environment towards the globalization of economies, the opening up of global markets, the network-free exchange of funds, knowledge and information, as well as the flexibility of the banking industry to accept new entrants and players in the industrial market, which obliged the banks to re-engineer their strategic choices and directions. Therefore, many of the leading global banks have committed to environmental sensing as a valuable and key tool for the success of reengineering of bank business processes, based on deep systemic perceptions of opportunities and the determinants of industry environment as well as businesses' resources and strategic capabilities.

Thus, the current study attempts to clarify the environmental sensing strategies of the Jordanian commercial banks, the impact of these strategies on achieving the organizational effectiveness and the speed of response to the variables and the reduction of environmental uncertainties.

\section{Study Problem and Questions}

Continuous change is an essential feature of the nature of commercial banking activities, which requires a rapid response through adaptation to this change, sensing and monitoring information as well as identifying opportunities and threats resulting from changes in the environment through developing and implementing the strategies due to their role in addressing complexities and changes and achieving long-term success.

According to the above discussion, the problem of the study is to identify whether there is "an impact of the strategies of environmental sensing on the organizational effectiveness: an applied study on Jordanian commercial banks".

Therefore, this study was developed to answer the following questions:

1. What is the impact of environmental sensing strategies on the organizational effectiveness in Jordanian commercial banks from the point of view of the respondents? 
2. What is the level of practicing environmental sensing strategies in Jordanian commercial banks from the point of view of respondents?

\section{The Importance of the Study}

This study derives its importance from the following points:

1. There are very few studies have dealt with this issue in the Arab environment, particularly in Jordanian context. For this reason it is important to examine this relationship in order to introduce new evidence and fill this gap in the administrative literature in the field of environmental sensing strategies, 2 . The study will open the way for researchers and interested parties to conduct research and future studies that will help organizations in the public and private sectors to strengthen the strategies of environmental sensing and their impact on the organizational effectiveness in the light of the findings and recommendations of the study.

\section{Study Objectives}

The current study seeks to identify the impact of environmental sensing strategies on the organizational effectiveness in Jordanian commercial banks. Out of this main objective, sub-goals emerge:

1. This study intended to determine the level of applying the concept of environmental sensing strategies in Jordanian commercial banks from the point of view of the respondents.

2. This study intended to determine the level of the concept of the organizational effectiveness in Jordanian commercial banks from the point of view of the respondents.

\section{Study Hypotheses}

The study seeks to test the validity of the following hypotheses:

\subsection{The Main Hypothesis}

There is no significant relationship between the effectiveness of projects management environmental sensing strategies (flexibility strategy, containment strategy, forecasting strategy) and the dimensions of organizational effectiveness (availability of information, stability) in Jordanian commercial banks. The following sub-hypotheses emerge from this hypothesis

\subsubsection{The First Sub-Hypothesis}

There is no significant relationship between the environmental sensing strategies (flexibility strategy, containment strategy, forecasting strategy) and availability of information as a dimension of the organizational effectiveness in Jordanian commercial banks.

\subsubsection{The Second Sub-Hypothesis}

There is no significant relationship between the environmental sensing strategies (flexibility strategy, containment strategy, forecasting strategy) and Stability as a dimension of the organizational effectiveness in Jordanian commercial banks.

\section{Literature Review}

\subsection{Concept Environmental Sensing}

The environmental sensing activity, or so-called (environmental monitoring and survey), is the process of searching for information in the environment and looking for opportunities and threats that may arise as a result of major changes in the general environment. The main function of Sensing is to collect important information, interpret them regularly and input the results of analysis in the process of strategic decision-making of the organization (Hareem, 2003).

The Sensing is also defined as: "Monitoring, evaluation and dissemination of information from the external and internal environment to key persons within the organization (Babatunde \& Adebisi, 2008).

Therefore, the environmental Sensing is interested in monitoring the environmental events outside and within the boundaries the organization, it analysis's the impact of the activities and operations in order to enable the organization to be succeed.

The main purpose of the analysis of the environment is (Yassen, 2010):

1. Identifying important forces in the environment that reflect opportunities and threats to the organization.

2. Planning and forecasting the changes that may occur to those forces in the future.

3. Classification of results of future forecasts to contribute in the decision-making process. 
Analysis of the external environment means the process of exploring factors and variables in order to identify the opportunities and threats in the external environment of the organization and to identify the sources and components of these opportunities and threats by fragmenting them into elements or sub-sections as well as understanding the mutual relations between them, on one hand, and between them and the business organization on the other hand. This will help them to establish an early warning system and prepare the necessary preparations before the potential threat appears at the right time, and to design efficient strategies capable of countering that threat and minimizing its negative impact, or turning it positively towards achieving the goals.

In addition, the main focus of the analyzing environment process is to examining opportunities that have to be achievement, and threats that should be avoided or dealt with if they do occur through the preparation of studies and research for all areas of the external environment (Gupta, 2013).

\subsection{Organizational Effectiveness}

The organizational effectiveness is defined as the ability of the organization to achieve the long and short term goals, which reflects the balance of power of influential parties and the interests of the parties concerned with the evaluation, as well as and the stage of growth and development experienced by the organization (Al-Qarouti, 2009). This ability and standards used to measure it depend on the model used to measure it.

Organizational effectiveness is defined as the ability of the organization to optimize the use of resources and to create a state of balance between internal factors and external influences, with full ability of adaptation to ensure achieving the objectives (Mohammedi, 2010).

The organizational effectiveness focuses on the objectives. The organizational effectiveness means that it can achieve its objectives (i.e. focusing on the goals as an indicator of determining the organizational effectiveness based on the available external environment resources and determining the nature of the objectives in terms of formal and non-formal, which is the degree of congruence between objectives within available resources) as well as remaining in the market despite competition (Nawar, 2006).

In general, effectiveness is the degree that the goals are achieved where the Organizational effectiveness means the degree of the organization objectives is achieved, in respect to the internal and external environmental determinants.

\subsubsection{Factors Affecting the Organizational Effectiveness}

The researchers and those interested in determining the meaning of the effectiveness differed in determining the factors affecting the organizational effectiveness and the degree of its impact

There is a group of factors that affect the organizational effectiveness, namely, (Al-Sirafi, 2006):

1. The Economic system: refers to the components that are directly related to the production of outputs, such as: division of labor, specialization in the division of labor, and the continuous basis of decision-making

2. The Political system: refers to the components or procedures within the organization that make decisions and try to obtain the influence and support for their decisions from the surrounding environment such as social acceptance of decisions and the legal and logical basis for decision-making.

3. The regulatory system: is the part of the organization that pushes its employees to comply with its objectives such as: the strict punishment system and communication.

4. The Environmental system: A set of determinants relating to population and environment that affect the organizational effectiveness in varying degrees and in different forms.

While Al-Shamma and Hamoud, (2007) see that the factors influencing the organizational effectiveness are:

1. Technical and technological factors, representing buildings, equipment, working conditions, organizational behavior and other factors of a general nature.

2. Factors related to human resources and include the morale of individuals and their attitudes and motives as well as the conflict and the working environment and its relations.

3. Factors related to the outputs of the organization and include feedback from beneficiaries or from the external environment such as the degree of its compatibility with their actual needs and its ability to provide saturation at the right time and place.

\subsubsection{The Environment of the Organization and Its Relationship with Organizational Effectiveness}

The environment is defined as: the set of circumstances under which the organization operates, and is divided into an internal and external environment". 
The internal environment: is the level of civilization, culture and values, which reflects the management method in determining the activity of the workers and their behavior. The managers cultivate this culture in their employees, and the organization derives its culture from the social environment in which it lives, and the civilization standards determine the extent of organizational effectiveness and the level of success.

The external environment: It refers to all external forces that affect the organization, and it is divided into two types:

1. The general environment: Long-term and indirect impact, such as political, legal, economic and technological conditions as well as social and global change.

2. The Activity environment: It includes dealers, competitors, trade unions, suppliers, partners, etc. The organization cannot operate in isolation from the surrounding environment. Rather, organizational effectiveness requires that the organization be an open system that ensures the continuity of the flow of inputs from the environment, and then turn them to outputs that return to the environment again to reach a state of equilibrium.

\subsection{Previous Studies}

(Tourah, 2018) study entitled "The Effect of Building the Organizational Structure on the Organizational Effectiveness in the Jordanian Ministries", a field study. The study found many results that showed that the level of availability of the dimensions of the organizational structure in the Jordanian ministries under study, from the point of view of the respondents, was at medium average, Also, the level of achieving the goals dimension, from the point of view of the respondents, was high, The results of the descriptive analysis showed that the level of organizational effectiveness in the Jordanian ministries, from the researchers' point of view, was medium, The study reached several recommendations stressing the need to grant staff specific and written powers, as required by the Formality dimension in the organizational structure. It also demands determining the nature of the functions of each unit in the organizational structure, and defining the tasks and duties of each department in the ministry. Similarly, Alawawdeh, (2017) conducted a study, entitled "The Effect of the Strategic Environmental Survey on the Total Organizational Effectiveness of Jordanian Chemical Industrial Companies". The study covered three dimensions of the strategic environmental survey: internal environment, industry environment, external environment, as well as four dimensions of organizational effectiveness: financial performance, customer service, internal processes, learning and growth, The study showed that the external environment analysis variable was the most influential on the indicators of the organizational effectiveness followed by the industry environment variable and finally the internal environment variable. The study concluded with a number of recommendations for the companies surveyed and for future research in light of its results.

Furthermore, Al-Jazi, (2017) studded the Effect of Bureaucratic Features on Enhancing the Organizational Effectiveness: A Field Study on the Employees in Jordanian Ministries" The study reached a number of results, the most important that there is a statistically significant effect of the dimensions of bureaucratic features on the dimensions of organizational effectiveness in Jordanian ministries. The study reached a number of recommendations, most important is: drawing of plans by the Jordanian ministries to prepare managers for the need to rapidly respond to new changes and enhance the ability of the Jordanian ministries to cope with emergency situations and circumstances.

(Abu Awrah, 2016) study, entitled "Environmental Sensing Strategies and their Impact on Achieving Strategic Flexibility for Managers of the Jordanian Phosphate Mines Company, The study reached a number of results, most important are that the level of applying the strategies of environmental sensing in Jordan Phosphate Mines Company has reached a high degree of application, and the level of achieving the strategic flexibility with its dimensions came high. Also, there is a statistically significant effect at the level of $(\alpha \leq 0.05)$ of the strategies of environmental sensing (strategy of closure, strategy of forecasting, strategy of gradation, strategy of rationalization) in achieving the strategic flexibility of Jordan Phosphate Mines Company, In the light of these results, the study recommends that the company be careful to develop more flexible plans capable of modifying the characteristics of the current products to suit customer requirements, undertake continuous changes and proactive strategies to cope with market changes.

By using a sample of Orange Jordan Mobile Telecommunications, Abu Sleem, (2014) examined the Impact of Environmental Sensing Strategies on Achieving Strategic Excellence. The study investigated the relationship between environmental sensing strategies (strategy of closure, strategy of gradation, forecasting strategy) and achieving Strategic Excellence in Orange Jordan Mobile Telecommunications Company, The study reached several results, the most prominent is that there is a positive effect of the strategies of environmental sensing (closure, gradation, forecasting) in achieving strategic excellence in its three dimensions: (Strategic sensitivity, exploratory innovation, optimal utilization of available opportunities) of Orange Jordan Mobile 
Telecommunications Company.

\section{Methodology}

This study is based on using the analytical descriptive method to review the most important literature related to the strategies of environmental sensing and the organizational effectiveness to cover the practical aspect of this study, through which the study tried to test the validity of its hypotheses, answer its questions and extract its results by relying on a questionnaire developed for this study In accordance with recognized practical steps.

\subsection{The Study Community}

The study community is composed of Jordanian commercial banks that perform a licensed economic activity, which were 12 banks. The number of managers was 240 managers in middle and lower management (the personnel department of the banks surveyed in 2018), through the comprehensive survey method as shown in the table below.

Table 1. Distribution of members of the study community according to the bank

\begin{tabular}{lllll}
\hline Number & Bank & $\begin{array}{l}\text { Distributed } \\
\text { questionnaires }\end{array}$ & $\begin{array}{l}\text { Retrieved } \\
\text { questionnaires }\end{array}$ & $\begin{array}{l}\text { Questionnaires } \\
\text { valid for analysis }\end{array}$ \\
\hline 1 & Arab Bank & 20 & 18 & 16 \\
2 & Jordan Ahli Bank & 20 & 16 & 13 \\
3 & Bank of Jordan & 20 & 13 & 11 \\
4 & Housing Bank for Trade and Finance & 20 & 16 & 14 \\
5 & Jordan Kuwait Bank & 20 & 18 & 16 \\
6 & Arab Jordan Investment Bank & 20 & 15 & 14 \\
7 & Commercial Bank of Jordan & 20 & 17 & 17 \\
8 & Invest Bank & 20 & 18 & 12 \\
9 & Arab Banking Corporation & 20 & 13 & 17 \\
10 & Bank al Etihad & 20 & 19 & 14 \\
11 & Society General de banque / Jordan & 20 & 14 & 15 \\
12 & Jordan Financial Bank & 20 & 17 & 175 \\
Total & & 240 & 194 & 10 \\
\hline
\end{tabular}

All members of the study community were surveyed from the workers in the middle and lower managements, where (240) questionnaires were distributed. (194) questionnaires were retrieved and (19) others were excluded due to their inefficiency in statistical analysis. Thus, the number of valid questionnaires which went through statistical analysis were (175) questionnaires which is (75\%) of the total number of questionnaires distributed, and it is considered acceptable rate for statistical analysis.

Table 2. Distribution of members of the study community according to personal and functional variables

\begin{tabular}{llcc}
\hline Variable & Variable categories & Number & Percentage \\
\hline Gender & Male & 101 & $57 \%$ \\
Age & Female & 74 & $43 \%$ \\
& 30 and younger & 81 & $46 \%$ \\
& $31-40$ years & 56 & $32 \%$ \\
Education & $41-50$ years & 19 & $11 \%$ \\
& 51 and above & 19 & $11 \%$ \\
& Diploma and less & 11 & $6 \%$ \\
Work Experience & Bachelor & 89 & $51 \%$ \\
& M.A. & 59 & $34 \%$ \\
& PhD & 16 & $9 \%$ \\
& 5 years and less & 55 & $31 \%$ \\
& 6-10 years & 59 & $34 \%$ \\
& $11-15$ years & 47 & $27 \%$ \\
\hline
\end{tabular}

\subsection{Validation}

The questionnaire was presented to a number of university faculty members to ascertain the veracity of the questionnaires.

\subsection{Stability of the Tool}

was extracted the internal consistency coefficient of the study tool for each dimension of the study's dimensions through using the (Cronbach's Alpha) coefficient 
Table 3. Values of Internal consistency coefficient of the Study tool paragraphs (Cronbach's Alpha) scale

\begin{tabular}{llll}
\hline Number & Dimension & Paragraphs number & Cronbach's Alpha value \\
\hline 1 & Flexibility Strategy & 5 & 0.719 \\
2 & Containment Strategy & 5 & 0.825 \\
3 & Forecasting Strategy & 5 & 0.736 \\
4 & Information Availability & 5 & 0.801 \\
5 & Stability & 5 & 0.790 \\
\hline 7.4 Statistical Processing & &
\end{tabular}

Used the statistical package (SPSS.16) In order to answer the study questions and test the validity of its hypotheses, descriptive and analytical statistical methods were used as follows:

Descriptive Statistic Measure: The Variance Inflation Factory (VIF) and (Tolerance) Test were used. The (Skewness) test was used to ensure that the data follows the (Normal Distributions). The (Multiple regression analysis) was used. The (Stepwise Multiple Regression Analysis) was used.

\section{Data Analysis \& Findings}

Table 4. Variance Inflation Factory test, Tolerance and Skewness

\begin{tabular}{llll}
\hline Dimensions of the independent Variable & VIF & Tolerance & Skewness \\
\hline Flexibility Strategy & 1.501 & .520 & 0.372 \\
Containment Strategy & 1.217 & .641 & -1.702 \\
Forecasting Strategy & 1.420 & .752 & -1.673 \\
\hline
\end{tabular}

We note that VIF values for all variables are less than 10 and range between (1.217-1.501) and Tolerance values ranged from $(0.520$ to 0.7520$)$, which is greater than $(0.05)$, and this an indicator that there wasn't high (multicollinearity) between the independent variables. It was ascertained that the data follow the normal distribution by calculating the (skewness) coefficient, where the values were close to the value of (0), which means less than (1), so, we can say that there is no real problem related to the normal distribution of the study data. In addition, the validity of the model for each individual hypothesis was ascertained. Table (5) shows the results.

Table 5. Results of (analysis of variance) to verify the validity of the model to test the hypotheses of the study

\begin{tabular}{|c|c|c|c|c|c|c|}
\hline $\begin{array}{l}\text { Dimensions of the } \\
\text { Dependent variable }\end{array}$ & Source & $\begin{array}{l}\text { Coefficient of } \\
\text { determination } \mathrm{R} 2\end{array}$ & $\begin{array}{l}\text { Total } \\
\text { Squares }\end{array}$ & $\begin{array}{l}\text { Average } \\
\text { squares }\end{array}$ & $\begin{array}{l}\text { F } \\
\text { calculated } \\
\text { value }\end{array}$ & $\begin{array}{l}\text { Level of } \\
\text { significance } \mathrm{F}\end{array}$ \\
\hline \multirow[t]{2}{*}{ Information availability } & Regression & \multirow[t]{2}{*}{0.495} & 60.504 & 20.300 & \multirow[t]{2}{*}{67.613} & \multirow[t]{2}{*}{$* * 0.00$} \\
\hline & Error & & 86.401 & .227 & & \\
\hline \multirow[t]{2}{*}{ Stability } & Regression & \multirow[b]{2}{*}{0.570} & 59.307 & 19.176 & \multirow[b]{2}{*}{126.411} & \multirow[b]{2}{*}{$* * 0.00$} \\
\hline & Error & & 48.716 & .136 & & \\
\hline
\end{tabular}

\section{** Statistical significant at the level of significance $(\alpha \leq 0.01)$}

Table (5) shows the validity of the model of testing the study hypotheses in terms of the calculated value of (F) and its associated level of significance at the level of significance $(\alpha \leq 0.01)$. The strategies of environmental sensing, explain (49.5\%) of the variance in the dimension (Information availability). It also explains (57.0\%) of the variance in the dimension (Stability).

All this confirms the impact of environmental sensing strategies on the interpretation of the dimensions of the organizational effectiveness. According to that, we can test the hypotheses of the study as follows:

\subsection{The Main Hypothesis}

There is no significant relationship between the effectiveness of projects management environmental sensing strategies (flexibility strategy, containment strategy, forecasting strategy) and the dimensions of organizational effectiveness (availability of information, stability) in Jordanian commercial banks.

Table 6. Results of (Analysis of Variance) to verify the validity of the model to test the first main hypothesis

\begin{tabular}{|c|c|c|c|c|c|c|}
\hline Source & Coefficient R2 & $\begin{array}{l}\text { Total } \\
\text { Squares }\end{array}$ & $\begin{array}{l}\text { Freedom } \\
\text { degrees }\end{array}$ & $\begin{array}{l}\text { Average } \\
\text { squares }\end{array}$ & $\begin{array}{l}\text { F calculated } \\
\text { value }\end{array}$ & Level of significance $F$ \\
\hline Regression & & 13.609 & 6 & 2.268 & & \\
\hline Error & 0.549 & 11.623 & 94 & & $* 17.336$ & 0.000 \\
\hline Total & & 25.232 & 100 & 0.124 & & \\
\hline
\end{tabular}

** Statistical significant at the level of significance $(\alpha \leq 0.05)$

The statistical results in the previous table indicate the validity of the model to test the main hypothesis and that there is a statistically significant effect at the level of significance $(\alpha \leq 0.05)$ of the environmental sensing 
strategies in its dimensions (flexibility strategy, containment strategy, forecasting strategy) on the organizational effectiveness in its dimensions (availability of information, stability), based on the $\mathrm{F}$ calculated value that reached (17.336) at a level of significance $(\alpha=0.000)$.

The statistical results in the same table show that the dimensions of the concept of environmental sensing strategies as an independent variable explain $(54.9 \%)$ of the variance in the dependent variable (Organizational Effectiveness), which is an explanatory power that reflects an acceptable degree of strength and stability of the study model. Therefore, we reject the study's main hypothesis as nihilistic, and accept the alternative hypothesis which states that there is an important statistically significant effect at the significance level of $(\alpha \leq 0.05)$ of the environmental sensing strategies (flexibility strategy, containment strategy, and forecasting strategy) on the organizational effectiveness (Information availability, Stability).

Table 7. Results of multiple regression analysis to test the impact of environmental sensing strategies and its different dimensions on the organizational effectiveness

\begin{tabular}{llccrc}
\hline $\begin{array}{l}\text { Dimensions of environmental } \\
\text { sensing Strategies }\end{array}$ & B & Standard Error & Beta & t value & $\begin{array}{l}\text { Significance } \\
\text { level }\end{array}$ \\
\hline Flexibility Strategy & 0.190 & 0.080 & 0.230 & $* 2.387$ & 0.019 \\
Containment Strategy & 0.223 & 0.091 & 0.262 & $* 2.462$ & 0.016 \\
Forecasting Strategy & 0.131 & 0.079 & 0.173 & 1.662 & 0.100 \\
\hline
\end{tabular}

** Statistical significant at the level of significance $(\alpha \leq 0.05)$

It is clear from the statistical results in the previous table and from the follow-up of (Beta) coefficients and (t) test that the dimensions of the independent variable (flexibility strategy and containment strategy), respectively, have a statistically significant effect on the dependent variable (organizational effectiveness) in terms of the (t) high calculated values in the previous table at the significance level of $(\alpha \leq 0.05)$ and the statistically significant influential power of (Beta) values.

The results in the table above indicated that there is no statistically significant effect of the independent variable (Forecasting strategy) on the dependent variable (the organizational effectiveness) in terms of the decrease in the calculated $(t)$ values shown in the previous table and the high level of significance over $(\alpha \leq 0.05)$ and the statistically significant influential power of (Beta) values.

Table 8. Results of the Stepwise Multiple Regression analysis to predict the organizational effectiveness through the dimensions of the environmental sensing strategies

\begin{tabular}{llcc}
\hline The order of entry of independent & $\mathrm{R} \mathrm{R}^{2}$ value & $\mathrm{t}$ calculated value & $\mathrm{t}$ significance level \\
Variables in the Forecasting equation & & $* 8.384$ & 0.000 \\
\hline Flexibility Strategy & 0.422 & $* 3.345$ & 0.001 \\
Containment Strategy & 0.481 &
\end{tabular}

** Statistical significant at the level of significance $(\alpha \leq 0.05)$

When applying the stepwise multiple regression analysis to determine the importance of each dimension of the independent coefficient individually in contributing to the mathematical model $y=a+b x$, which represents the effect of the dimensions of the concept of environmental sensing strategies on the organizational effectiveness, the previous table explains the order of entry of the dimensions of the independent coefficient in the regression equation. The Flexibility Strategy dimension ranked first and explained (42.2\%) of the variance in the dependent variable (the organizational effectiveness) followed by the Containment strategy dimension, which explained with the Flexibility strategy Dimension, (48.1\%) of the variance in the dependent variable (the organizational effectiveness). The Forecasting strategy came out of the Forecasting equation.

\subsubsection{The Results of Testing the First Sub-Hypothesis}

There is no significant relationship between the environmental sensing strategies (flexibility strategy, containment strategy, forecasting strategy) and availability of information as a dimension of the organizational effectiveness in Jordanian commercial banks.

Table 9. Results of Analysis of Variance to validate the validity of the model to test the first sub-hypothesis

\begin{tabular}{lcccccc}
\hline Source & $\begin{array}{l}\text { Coefficient } \\
\text { R2 }\end{array}$ & $\begin{array}{l}\text { Total } \\
\text { Squares }\end{array}$ & $\begin{array}{l}\text { Freedom } \\
\text { degree }\end{array}$ & $\begin{array}{l}\text { Average } \\
\text { squares }\end{array}$ & F calculated value & $\begin{array}{l}\text { Level of significance } \\
\text { F }\end{array}$ \\
\hline Regression & & 15.721 & 6 & 2.620 & & \multirow{2}{*}{0.000} \\
Error & 0.523 & 14.647 & 94 & 0.156 & $* 15.721$ & \\
Total & & 30.368 & 100 & & & \\
\hline
\end{tabular}

** Statistical significant at the level of significance $(\alpha \leq 0.05)$

The statistical results in the previous table indicate the validity of the model to test the first sub-hypothesis and 
that there is a statistically significant effect at the level of significance $(\alpha \leq 0.05)$ of the environmental sensing strategies (flexibility strategy, containment strategy, forecasting strategy) on the availability of information as a dimension of the organizational effectiveness, based on the calculated value of $(F)$ which reached (15.721) at the level of significance $(\alpha=0.000)$.

The statistical results in the same table show that the dimensions of the environmental sensing strategies as an independent variable explain (52.3\%) of the variance in the dependent variable( availability of information), which is a medium explanatory power that reflects an acceptable degree of the stability and strength of the study model. So, we reject the study first sub-hypothesis as nihilistic, and accept the alternative hypothesis that states that there is a statistically significant effect at the level of significance $(\alpha \leq 0.05)$ of the environmental sensing strategies (flexibility strategy, containment strategy, forecasting strategy) on the availability of information as a dimension of the organizational effectiveness.

Table 10. The results of the multiple regression analysis to test the impact of environmental sensing strategies and their various dimensions on the availability of information as a dimension of the organizational effectiveness

\begin{tabular}{llcrrr}
\hline $\begin{array}{c}\text { Dimensions of environmental } \\
\text { sensing Strategies }\end{array}$ & B & Standard Error & Beta & t value & Significance level \\
\hline Flexibility Strategy & 0.470 & 0.102 & 0.504 & $* 3.917$ & 0.000 \\
Containment Strategy & 0.247 & 0.074 & 0.295 & $* 3.422$ & 0.001 \\
Forecasting Strategy & 0.123 & 0.089 & 0.148 & 1.383 & 0.170 \\
\hline
\end{tabular}

** Statistical significance at the level of significance $(\alpha \leq 0.05)$

It is clear from the statistical results in the previous table and from the follow-up of (Beta) coefficients and the (t) test, that the dimensions of the independent variable (flexibility strategy, containment strategy), respectively, have a statistically significant effect on the dependent variable (availability of information) in terms of the high calculated values of $(t)$ as shown in the previous table at the level of significance $(\alpha \leq 0.05)$ and the statistically significant influential power of the values of (Beta).

The results in the table above indicate that there is no statistically significant effect of the independent variable (forecasting strategy) on the dependent variable (availability of information) in terms of the low calculated values of $(t)$ in the previous table at the level of significance $(\alpha \leq 0.05)$ and the statistically significant influential power of the values of (Beta).

Table 11. The results of Step Wise Multiple Regression analysis to predict the availability of information through the dimensions of the environmental sensing

\begin{tabular}{llll}
\hline The order of entry of independent & $\mathrm{R}^{2}$ value & $\mathrm{t}$ calculated value & $\mathrm{t}$ significance level \\
Variables in the Forecasting equation & & & \\
\hline Flexibility Strategy & 0.438 & $* 7.978$ & 0.000 \\
Containment Strategy & 0.462 & $* 4.104$ & 0.002 \\
\hline
\end{tabular}

** Statistical significance at the level of significance $(\alpha \leq 0.05)$

When performing the Stepwise Multiple Regression analysis to determine the importance of each dimension of the independent factor in contributing to the mathematical model that represents the effect of the dimensions of the environmental sensing strategies on the availability of information, the table above shows the order of entry of the dimensions of the independent factor into the regression equation.

The Flexibility strategy came first and explained (43.8\%) of the variance in the dependent variable (availability of information), followed by the containment strategy, which explained with the Flexibility strategy (46.2\%) of the variance in the dependent variable (availability of information). The (Forecasting strategy) came out of the forecasting equation.

\subsubsection{Results of Testing the Second Sub-Hypothesis}

There is no significant relationship between the environmental sensing strategies (flexibility strategy, containment strategy, forecasting strategy) and Stability as a dimension of the organizational effectiveness in Jordanian commercial banks.

Table 12. Results of Analysis of Variance to verify the validity of the model to test the second sub-hypothesis

\begin{tabular}{lcccccc}
\hline hghf & Coefficient R2 & $\begin{array}{l}\text { Total } \\
\text { Squares }\end{array}$ & $\begin{array}{l}\text { Freedom } \\
\text { degrees }\end{array}$ & $\begin{array}{l}\text { Average } \\
\text { squares }\end{array}$ & $\begin{array}{l}\text { F calculated } \\
\text { value }\end{array}$ & $\begin{array}{l}\text { Level } \\
\text { significance F }\end{array}$ \\
\hline Regression & & 13.898 & 6 & 2.316 & & \\
Error & 0.442 & 16.465 & 94 & 0.175 & $* 14.116$ & 0.000 \\
Total & & 30.364 & 100 & & 00 & \\
\hline
\end{tabular}

** Statistical significance at the level of significance $(\alpha \leq 0.05)$ 
The statistical results in the previous table indicate the validity of the model to test the second sub-hypothesis and that there is a statistically significant effect at the level of significance $(\boldsymbol{\alpha} \leq \mathbf{0 . 0 5})$ of the environmental sensing strategies (flexibility strategy, containment strategy, forecasting strategy) on Stability as a dimension of the organizational effectiveness, based on the calculated value of $(F)$, which reached (14.116) at the level of significance $(\alpha=0.000)$.

The statistical results in the same table also show that the dimensions of the strategies of the environmental sensing as an independent variable explain the $(44.2 \%)$ of the variance in the dependent variable (Stability ), which is a medium explanatory power that reflects an acceptable degree of the strength and stability of the study model.

Accordingly, we reject the study's second sub-hypothesis as nihilistic, and accept the alternative hypothesis that: There is an important statistically significant effect at the level of significance $(\alpha \leq 0.000)$ of the environmental sensing strategies (flexibility strategy, containment strategy, Forecasting strategy) on the Stability as a dimension of the organizational effectiveness.

Table 13. The results of multiple regression analysis to test the impact of environmental sensing strategies, and various dimensions, on stability as a dimension of the organizational effectiveness

\begin{tabular}{llcccc}
\hline $\begin{array}{c}\text { Dimensions of environmental } \\
\text { sensing Strategies }\end{array}$ & B & Standard Error & Beta & t value & $\begin{array}{l}\text { Significance } \\
\text { level }\end{array}$ \\
\hline Flexibility Strategy & 0.206 & 0.095 & 0.228 & 2.142 & 0.028 \\
Containment Strategy & 0.193 & 0.094 & 0.232 & 2.001 & 0.036 \\
Forecasting Strategy & 0.205 & 0.108 & 0.220 & 1.905 & 0.060 \\
\hline
\end{tabular}

** Statistical significance at the level of significance $(\alpha \leq 0.05)$

It is clear from the statistical results presented in the previous table, and from the follow-up of (Beta) coefficients, and the (t) test that the dimensions of the independent variable (flexibility strategy and containment strategy) respectively have a statistically significant effect on the dependent variable (stability) in terms of the significance and high calculated values of $(t)$, as shown in the previous table, at the significance level of $(\alpha \leq 0.05)$ and the statically significant influential power of (Beta) values.

The results in the table above indicate that there is no statistically significant effect of the dimension of the independent variable (forecasting strategy) on the dependent variable (stability) in terms of the decrease in the calculated values of (t), as shown in the previous table, at the significance level of $(\alpha \leq 0.05)$ and the statically significant influential power of (Beta) values.

Table 14. Results of Step Wise Multiple Regression analysis, to predict stability through the dimensions of environmental sensing strategies

\begin{tabular}{llcl}
\hline The order of entry of independent & & t calculated value & t significance level \\
Variables in the Forecasting equation & $\mathrm{R}^{2}$ value & $* 7.171$ & 0.000 \\
\hline Flexibility Strategy & 0.331 & $* 3.015$ & 0.003 \\
Containment Strategy & 0.376 & & \\
\hline
\end{tabular}

** Statistical significance at the level of significance $(\alpha \leq 0.05)$

In the analysis of the stepwise multiple regression, to determine the importance of each dimension of the independent factor in contributing to the mathematical model that represents the effect of the dimensions of the strategies of environmental sensing on stability, the table above shows the order of entry of the dimensions of the independent factor into the regression equation. The flexibility strategy ranked first and explained (33.1\%) of the variance in the dependent variable (stability). Finally, the containment strategy dimension entered and explained with the flexibility strategy dimension $(37.6 \%)$ of the variance in the dependent variable (stability). The forecasting strategy came out of the forecasting equation.

\subsection{Conclusion}

1. The results showed that there is an important statistically significant effect at the level of significance $(\boldsymbol{\alpha} \leq \mathbf{0 . 0 5})$ of the environmental sensing strategies (flexibility strategy, containment strategy, forecasting strategy) combined on the organizational effectiveness. What explains this result is that the awareness of employees in the upper and middle managements of Jordanian commercial banks of environmental sensing strategies directs the organization to respond quickly to opportunities and threats in changing environmental conditions, create conditions that support innovation, generate ideas and innovations and establish control systems in advance, which help in achieving the organizational effectiveness.

Individually, the dimensions of the independent variable (flexibility strategy and containment strategy) 
respectively had a statistically significant effect on the dependent variable (the organizational effectiveness), whereas there was no statistically significant effect of the dimension of the independent variable (forecasting strategy) on the dependent variable (organizational effectiveness).

2. The results indicated that there is a statistically significant effect at the level of significance $(\boldsymbol{\alpha} \leq \mathbf{0 . 0 5})$ of the environmental sensing strategies (flexibility strategy, containment strategy, forecasting strategy) on the availability of information as a dimension of the organizational effectiveness. This result explains that the awareness of employees in the upper and middle managements of Jordanian commercial banks of environmental sensing strategies contributes to the organization's ability to manage change in the organizational and administrative structure by dividing and defining administrative levels, scope of supervision, redesigning relationships and coordinating tasks to achieve stability and improve performance.

The results showed that the dimensions of the independent variable (flexibility strategy and containment strategy) individually and respectively had a statistically significant effect on the dependent variable (availability of information). The results also indicated that there was no statistically significant effect of the dimension of the independent variable (forecasting strategy) on the dependent variable (availability of information).

3. The results also indicated that there is a statistically significant effect at the level of significance $(\boldsymbol{\alpha} \leq \mathbf{0 . 0 5})$ of the environmental sensing strategies (flexibility strategy, containment strategy, forecasting strategy) on stability as a dimension of the organizational effectiveness. This means that Jordanian commercial banks are capable of providing all the elements that guarantee the satisfaction of their employees. This is due to a number of factors including the banks' ability to adapt and innovate in solving problems, respond to changes in the demands and needs of the market and to have mutual trust and respect between employees and bosses. These factors had an impact in increasing the level of job satisfaction for employees in Jordanian commercial banks.

The results also showed that the dimensions of the independent variable individually (flexibility strategy and containment strategy), respectively, had a statistically significant effect on the dependent variable (stability). The results also indicated that there was no statistically significant effect of the dimension of the independent variable (forecasting strategy) on the dependent variable (stability).

\section{Conclusions}

This study aims to examine the effect of environmental sensing strategies on the organizational effectiveness among Jordanian commercial banks. Results of the study show that, the level of applying environmental sensing strategies in Jordanian commercial banks has reached a high level. The level of organizational effectiveness in Jordanian commercial banks, has also reached a high level. There is a statistically significant impact of environmental sensing strategies (flexibility strategy, containment strategy, and forecasting strategy) on the organizational effectiveness as a whole and on its dimensions, individually, (availability of information, stability). The study has several limitations, such as the sample of the study focus on the Banking sector, while, future studies could be focus on non-financial sectors. Also, the current study examined this relationship among Jordanian companies. Future research might be consider another sample. Based on the previous findings, the current study presents the following recommendations:

1. The Jordanian commercial banks shall make the best use of their human resources capabilities by training and qualifying their managers in how to practice environmental sensing strategies in the external environment to achieve organizational effectiveness.

2. The Authority should ensure that the necessary information about the surrounding environment is collected prior to any structural change it intends to undertake.

3. Create a system of incentives and rewards for employees to motivate them to work and to demonstrate the distinguished abilities to interpret and clarify information in a way that serves the organization.

4. The need to focus on the skills of leaders in Jordanian commercial banks by focusing on the outstanding capabilities in clarifying the new knowledge in a way that enhances the potential to use this knowledge in boosting the competitive position and competitive advantage.

5. Provide scientific references in the field of environmental sensing strategies for researchers and scholars to facilitate the preparation of research and studies.

\section{References}

Abu Awrah, A. (2016). Environmental Sensing Strategies and their Impact on achieving Strategic Flexibility, a field study on Jordan Phosphate Mines Company. Unpublished Master Thesis, University of Mu'tah, Karak, the Hashemite Kingdom of Jordan. 
Abu Sleem, A. (2014). Impact of Environmental Sensing Strategies on Achieving Strategic Excellence, a case study on Orange Jordan Mobile Telecommunications Company. Unpublished MA thesis, Middle East University, Amman, Jordan.

Alawawdeh, W. M. (2017). The impact of the strategic environmental survey on the total organizational effectiveness of the industrial companies.Jordanian Chemistry. Al-Manara Magazine for Research and Studies, 23(1).

Al-Jazi, K. S. (2017). The Effect of Bureaucratic Features on Enhancing Organizational Effectiveness: A Field Study on Employees in Jordanian Ministries. Unpublished Master Thesis, University of Mu'tah, Karak, the Hashemite Kingdom of Jordan.

Al-Qarouti, M. Q. (2009). Organization and Regulation Theory, Third Edition, Amman, Wael Dar for Publishing House.

Al-Shamma, K., \& Hamoud, K. (2007). Organization Theory, Amman: Al-Masirah Dar for Publishing and Distribution.

Al-Sirafi, M. (2006). Organizational Behavior, Alexandria: Horus International Foundation for Publishing and Distribution.

Babatunde, B. O., \& Adebisi, A. O. (2008). Strategic Environmental Scanning and Organization Performance in a Competitive Business Environment. Economic Insights - Trends and Challenges, LXIV(1).

Gupta, A. (2013). Environment and pest analysis: an approach to external business environment. Merit Research Journal of Art, Social Science and Humanities, 1(2).

Hareem, H. (2003). Organization Management. Edition 1, Amman: Al-Hamed Dar for Publishing and Distribution.

Mohammedi, S. (2010). The relationship between strategic choice and organizational structure, and its impact on organizational effectiveness, unpublished $\mathrm{PhD}$ thesis, St. Clements International University.

Nawar, S. (2006). The Effectiveness of Organization in Economic Institutions, Communication sociology laboratory for research and translation, Riyadh, Saudi Arabia.

Tourah, M. A. (2018). The Effect of Building the Organizational Structure on the Organizational Effectiveness in the Jordanian Ministries. A field study. Unpublished Master Thesis, University of Mu'tah, Karak, Hashemite Kingdom of Jordan.

Yassen, S. G. (2010). Strategic management, Amman, Jordan, AL yazori publishing house.

\section{Copyrights}

Copyright for this article is retained by the author(s), with first publication rights granted to the journal.

This is an open-access article distributed under the terms and conditions of the Creative Commons Attribution license (http://creativecommons.org/licenses/by/4.0/). 